\title{
BMJ Open Pharmacy study of natural health product adverse reactions (SONAR): a cross-sectional study using active surveillance in community pharmacies to detect adverse events associated with natural health products and assess causality
}

Candace Necyk, ${ }^{1}$ Ross T Tsuyuki, ${ }^{2}$ Heather Boon, ${ }^{3}$ Brian C Foster, ${ }^{4}$ Don LeGatt, ${ }^{5}$ George Cembrowski, ${ }^{6}$ Mano Murty, ${ }^{7}$ Joanne Barnes, ${ }^{8}$ Theresa L Charrois, ${ }^{9}$ John T Arnason, ${ }^{10}$ Mark A Ware, ${ }^{11}$ Rhonda J Rosychuk, ${ }^{12}$ Sunita Vohra ${ }^{12}$

To cite: Necyk C, Tsuyuki RT, Boon $\mathrm{H}$, et al. Pharmacy study of natural health product adverse reactions (SONAR): a cross-sectional study using active surveillance in community pharmacies to detect adverse events associated with natural health products and assess causality. BMJ Open 2014;4:e003431. doi:10.1136/bmjopen-2013003431

- Prepublication history for this paper is available online. To view these files please visit the journal online (http://dx.doi.org/10.1136/ bmjopen-2013-003431).

Received 17 June 2013 Revised 18 February 2014 Accepted 20 February 2014

CrossMark

For numbered affiliations see end of article.

Correspondence to Dr Sunita Vohra; svohra@ualberta.ca

\section{ABSTRACT}

Objectives: To investigate the rates and causality of adverse event(s) (AE) associated with natural health product (NHP) use, prescription drug use and concurrent NHP-drug use through active surveillance in community pharmacies.

Design: Cross-sectional study of screened patients. Setting: 10 community pharmacies across Alberta and British Columbia, Canada from 14 January to 30 July 2011.

Participants: The participating pharmacy staff screened consecutive patients, or agents of patients, who were dropping or picking up prescription medications.

Primary outcome measures: Patients were screened to determine the proportions of them using prescription drugs and/or NHPs, as well as their respective AE rates. All AEs reported by the screened patients who took a NHP, consented to, and were available for, a detailed telephone interview $(14 \%)$ were adjudicated fully to assess for causality.

Results: Over a total of 105 pharmacy weeks and 1118 patients screened, 410 patients reported taking prescription drugs only $(36.7 \%$; $95 \% \mathrm{Cl} 33.9 \%$ to $39.5 \%), 37$ reported taking NHPs only $(3.3 \% ; 95 \% \mathrm{Cl}$ $2.4 \%$ to $4.5 \%$ ) and 657 reported taking prescription drugs and NHPs concurrently $(58.8 \% ; 95 \% \mathrm{Cl} 55.9 \%$ to $61.6 \%$ ). In total, 54 patients reported an AE, representing $1.2 \%$ (95\% $\mathrm{Cl} 0.51 \%$ to $2.9 \%), 2.7 \%$ (95\% $\mathrm{Cl} 0.4 \%$ to $16.9 \%)$ and $7.3 \%(95 \% \mathrm{Cl} 5.6 \%$ to $9.6 \%$ ) of each population, respectively. Compared with patients who reported using prescription drugs, the patients who reported using prescription drugs and NHPs concurrently were 6.4 times more likely to experience an $\mathrm{AE}(\mathrm{OR} ; 95 \% \mathrm{Cl} 2.52$ to 16.17; $p<0.001)$. Combined with data from Ontario, Canada, a national proportion was calculated, which found that

\section{Strengths and limitations of this study}

- Active surveillance likely detects adverse events (AEs) due to natural health product (NHP) and prescription drug use at a higher rate than passive surveillance alone, the system that is currently employed by most of the regulatory agencies around the world.

- Patient interviews allowed for meaningful information to be collected to allow for full causality assessment of an AE; laboratory analysis supported this assessment.

- The AE rate in patients taking NHPs and prescription drugs concurrently could be compared with those taking prescription drugs alone.

- The first national data were analysed for this hypothesis across Canada.

- Data in British Columbia are not consistent with Alberta and Ontario.

- Risk for possible biases (recall bias, selection bias) due to observational study design.

- High loss to follow-up rate occurred between the screening and patient interview phases.

$45.4 \%$ (95\% Cl $43.8 \%$ to $47.0 \%$ ) of Canadians who visit community pharmacies take NHPs and prescription drugs concurrently, and of those, $7.4 \%$ (95\% Cl 6.3\% to 8.8\%) report an $\mathrm{AE}$.

Conclusions: A substantial proportion of community pharmacy patients use prescription drugs and NHPs concurrently; these patients are at a greater risk of experiencing an AE. Active surveillance provides a means of detecting such AEs and collecting highquality data on which causality assessment can be based. 


\section{INTRODUCTION}

The use of natural health products (NHPs) is popular worldwide. $^{1-3}$ Recent surveys in North America, Australia and Europe have found that at least half of the population use NHPs, defined by Health Canada, Canada's federal regulatory agency, as any vitamin, mineral, herbal remedy, homeopathic medicine, traditional medicine, probiotic, amino acid or fatty acid product. ${ }^{1}{ }^{4-7}$ NHPs have become the second most purchased over-the-counter (OTC) product in Canada in 2012, next to headache and pain relief products. ${ }^{2}$ Reasons for use are multifactorial, including an increased interest in natural approaches focused on prevention, media advertising and increased concern with taking synthetic drugs. ${ }^{1} 8$ Healthcare professionals are following this trend in their practices as well, with $38 \%$ of physicians now recommending NHPs to their patients and $89 \%$ of pharmacists spending more than $30 \mathrm{~min} /$ day counselling on these products. ${ }^{9} 10$

With increasing NHP use, the concern for consumer safety is also growing. ${ }^{3} 1112$ Typically, NHPs are considered by users to be safe since they are "natural"13; however, studies demonstrate some serious toxicities and many possible adverse reactions (ARs) with the use of these products. ${ }^{3}{ }^{11-15}$ Further, NHP use is higher among patients with chronic medical conditions, ${ }^{16}{ }^{17}$ where prescription drug use is likely: $58 \%$ of cardiovascular patients taking narrow therapeutic index drugs used NHPs and prescription drugs concurrently, ${ }^{18}$ compared with $39.7 \%$ of community pharmacy patients screened in Ontario (ON) ${ }^{19}$ In patients over 50 years old, $87.4 \%$ of those taking NHPs did so in combination with drugs. ${ }^{20}$ Such patients are at greater risk of drug interactions, ${ }^{21}$ and therefore ARs.

In regulatory agencies worldwide, passive surveillance systems are employed to detect postmarketing ARs. ${ }^{22}$ These systems rely on spontaneous reports of suspected ARs by consumers, health professionals and industry. ${ }^{23}$ While this type of postmarketing surveillance allows for the detection of ARs in 'real-world' conditions, it depends on individuals recognising when an adverse event (AE) should be reported and their knowledge to submit a high-quality report for interpretation and assessment. ${ }^{22} 23$ Of note, an $\mathrm{AE}$ becomes an $\mathrm{AR}$ when causation is suspected to be due to a health product. ${ }^{24}$ An $\mathrm{AE}$ encompasses any unfavourable or unintended sign, symptom or disease associated with the use of a medicinal product, whether or not considered related to the product itself. ${ }^{24}$ It is estimated that only $1-10 \%$ of all AEs are ever captured by passive surveillance systems. ${ }^{23}$

Detection of AEs associated with NHPs is further complicated by physicians and pharmacists who do not consistently inquire about NHP use during medical history-taking, and reporting NHP-related AEs less often than AEs associated with prescription drugs or OTC drugs. ${ }^{9}{ }^{25}$ In addition, many patients choose not to disclose NHP use to their healthcare providers, or to report to them about suspected adverse drug reactions associated with these products. ${ }^{12}$ Evidence suggests that one-third of patients are unaware of any risk associated with NHPs. ${ }^{26}$

An alternative system, or one that can be used to complement passive surveillance, is increasingly being identified as necessary to mitigate the harms to patients. ${ }^{23}$ Worldwide active surveillance systems, such as the Sentinel initiative to monitor postmarket risk analysis of health products in the USA and the National Cancer Registry in the UK, are proving to be a successful means of collecting AR data. ${ }^{23}$ A method of active surveillance that still appears underutilised, however, is the process of building $\mathrm{AE}$ detection screening into health professionals' practice.

Pharmacy study of NHP ARs (SONAR) is a multicentre population-based observational study in which researchers partnered with Health Canada and community pharmacists and pharmacies to implement an active surveillance screening system to detect AEs associated with NHPs experienced by patients at this setting. ${ }^{19}$ A pilot study in ON, Canada, found that $39.7 \%$ of patients were taking NHPs and prescription drugs concurrently, of which $7.4 \%$ reported an AE. ${ }^{19}$ This represented at least a 3000-fold higher rate of ARs than that captured by Health Canada's passive surveillance system over a corresponding time period. The Pharmacy SONAR pilot study was limited, however, by the lack of comparable data for patients taking prescription drugs or NHPs alone. $^{19}$

Pharmacy SONAR was expanded to Alberta $(\mathrm{AB})$ and British Columbia (BC), Canada, to investigate the rate of each prescription drug, NHP and concurrent prescription drug-NHP use, and their respective AE rates, through an active surveillance model in community pharmacies across Western Canada. Our objective was to further assess the feasibility of implementing active surveillance into community pharmacy practices and to calculate a national proportion of patients using prescription drugs and NHPs concurrently, as well as the proportion of those reporting an $\mathrm{AE}$.

\section{METHODS}

A two-phase cross-sectional model, as detailed in the ON pilot study, ${ }^{19}$ was maintained for the purpose of this study. Phase I involved the implementation of active surveillance in community pharmacies and data collection through patient interviews; phase II involved AE causality assessment and laboratory analysis where appropriate.

\section{Phase I: active surveillance}

Community pharmacists volunteered to participate. In-store training and all relevant study materials, such as screening logs and patient information packages, were provided to each community pharmacy site. Each site received a copy of an authoritative reference text, Natural Standard ${ }^{27}$ and a NHP-drug interaction grid $^{28}$ (created for the pilot study) to support knowledge in 
this area. Staff were provided follow-up and assistance through remote support (ie, telephone contact), as compared with in-person support by the $\mathrm{ON}$ study ${ }^{19}$ to assess for continued feasibility with less intervention.

All consecutive patients bringing prescriptions or collecting medication for themselves (or for a child or other close family member) at a participating pharmacy were included in the study. Pharmacists and pharmacy staff asked such patients three questions on the screening log (figure 1). The patients unable to communicate in English were excluded. NHPs were defined in accordance with Health Canada's definition: any vitamin, mineral, herbal remedy, homeopathic medicine, traditional medicine, probiotic, amino acid or fatty acid product. ${ }^{7}$ One month was chosen as a suitable screening history period to capture AEs following product use to minimise recall bias. If the patient answered yes to questions 2 and 3, they received a study information package. If the patient agreed to participate in follow-up, written consent was obtained by a pharmacy staff member and the study pharmacist was notified. Community pharmacy staff did not assess causality of any reported AE.

The study pharmacist $(\mathrm{CN})$ conducted a detailed telephone interview with consenting patients within 1 week of their reporting an $\mathrm{AE}(\mathrm{s})$. Verbal consent was obtained at the start of the interview. The interview comprised questions detailing medical conditions, all drug and NHP use and details around the $\mathrm{AE}(\mathrm{s})$. The interview form was adapted from the pilot study to include additional details of the NHPs (ie, how they were prepared, when relevant). A copy of the interview form is available from the corresponding author on request. The medical history of 3 months was collected through a telephone interview, allowing for more extensive data to lend knowledge to the overall causality assessment. If deemed necessary, the patient was asked to provide samples of the NHPs and drugs taken at the time of the $\mathrm{AE}(\mathrm{s})$ for laboratory analysis in phase II and for consent to report the $\mathrm{AE}(\mathrm{s})$ to Health Canada, if this had not already been done.

\section{Phase II: causality assessment and laboratory analysis}

All interviewed cases were summarised and adjudicated by a three-member committee: one clinical NHP expert, one basic science NHP expert and a committee chair

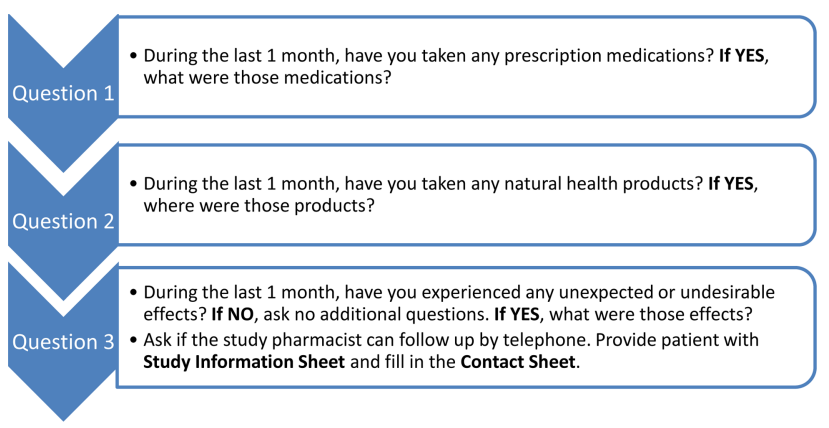

Figure 1 Patient screening questions.
(SV) knowledgeable in both areas. The two experts independently assessed each case based on the WHO Causality Assessment Criteria, ${ }^{29}$ the Naranjo Probability Scale $^{30}$ and the Horn Drug Interaction Probability Scale. $^{31}$ In each instance, consensus was reached through discussion. Two laboratories were available for undertaking the following analyses in this study: (1) NHP constituent assessment and (2) adulteration/contamination assessment. The laboratories tested the samples provided by the participants, and if the samples were unavailable, similar products from the same lot or batch were tested.

\section{Statistical analysis}

Phase I data were used to calculate proportions by pharmacy. A weighted average proportion for each outcome with the associated 95\% CIs were provided using a logistic regression with intercept only model. ORs and the associated $95 \%$ CIs for $\mathrm{AE}$ rates for participants using NHPs only and NHP-prescription drugs concurrently, compared with prescription drug use only, were calculated using logistic regression. Stata V.12.0 was used for all analyses. ${ }^{32}$

\section{RESULTS}

\section{Phase I: active surveillance}

Ten pharmacies across $\mathrm{AB}(\mathrm{n}=7)$ and $\mathrm{BC}(\mathrm{n}=3)$ participated in the study. Over a period of 105 pharmacy weeks (14 January to 30 July 2011), 1118 patients were screened. Tables 1 and 2 show proportions of patients screened using NHPs and/or prescription drugs and those reporting AEs, respectively. The results were similar when the responders with incomplete screening data (ie, each of the three questions were not filled in) were included in the denominator of the analysis; therefore, the results are reported including all patients screened.

When compared with taking prescription drugs alone, patients taking concurrent NHP-prescription drugs were 6.38 (95\% CI 2.52 to $16.17 ; \mathrm{p}<0.001)$ times more likely to experience an $\mathrm{AE}$. When looking at $\mathrm{AB}$ separately, the OR was 4.78 (95\% CI 1.88 to 12.16 ; $\mathrm{p}<0.001$ ); an OR could not be provided for $\mathrm{BC}$ due to having no $\mathrm{AE}$ reports in the exposure reference group (prescription drugs only). Table 3 provides ORs for each province, where such analysis was possible. Similarly, data could not be further stratified by pharmacy due to a lack of $\mathrm{AE}$ reports in the exposure reference group in some pharmacies. Nearly half $(\mathrm{n}=17 ; 34.0 \%)$ of the patients reporting an $\mathrm{AE}$, while also taking a NHP, consented to be contacted for a detailed interview, of whom 7 (14.0\%) were interviewed. Four patients reporting an AE with NHP use were referred to the study for causality assessment. All four patients were interviewed and underwent phase II of the study; however, they were not included in the phase I analysis since they were not screened at a 
Table 1 Weighted proportions of participants using prescription drugs, NHPs or both, by pharmacy and province

\begin{tabular}{|c|c|c|c|c|c|}
\hline & Pharmacy & Participants $\left(\mathbf{n}_{\mathbf{i}}\right)$ & $\begin{array}{l}\text { Prescription drug } \\
\text { use only }\left(n_{p}\right)\left(p_{p}\right)\end{array}$ & $\begin{array}{l}\text { NHP use } \\
\text { only }\left(n_{n}\right)\left(p_{n}\right)\end{array}$ & $\begin{array}{l}\text { Concurrent } \\
\text { use }\left(n_{c}\right)\left(p_{c}\right)\end{array}$ \\
\hline & AB01 & 113 & $38(33.6 \%)$ & $3(2.6 \%)$ & $72(63.7 \%)$ \\
\hline & AB02 & 119 & $33(27.7 \%)$ & $9(7.6 \%)$ & $75(63.0 \%)$ \\
\hline & AB03 & 101 & $32(32.0 \%)$ & $4(4.0 \%)$ & $64(63.4 \%)$ \\
\hline & AB04 & 312 & $74(23.7 \%)$ & $10(3.2 \%)$ & $222(71.2 \%)$ \\
\hline & AB05 & 10 & $2(20.0 \%)$ & $2(20.0 \%)$ & $5(50.0 \%)$ \\
\hline & AB06 & 181 & $74(40.9 \%)$ & $0(0.0 \%)$ & $107(59.1 \%)$ \\
\hline & AB07 & 44 & $16(36.4 \%)$ & $5(11.4 \%)$ & $23(52.3 \%)$ \\
\hline \multirow[t]{5}{*}{ Alberta total } & & 880 & $270(30.7 \%)$ & $33(3.8 \%)$ & $568(64.6 \%)$ \\
\hline & & & $(95 \% \mathrm{Cl} 27.7$ to 33.8$)$ & (95\% Cl 2.7 to 5.2$)$ & (95\% Cl 61.3 to 67.6$)$ \\
\hline & BC01 & 149 & $104(69.8 \%)$ & $3(2.0 \%)$ & $37(24.8 \%)$ \\
\hline & $\mathrm{BC} 02$ & 58 & $33(56.9 \%)$ & $0(0.0 \%)$ & $25(43.1 \%)$ \\
\hline & $\mathrm{BCO3}$ & 31 & $3(9.7 \%)$ & $1(3.2 \%)$ & $27(87.1 \%)$ \\
\hline \multirow[t]{2}{*}{ British Columbia total } & & 238 & $140(58.8 \%)$ & $4(1.7 \%)$ & $89(37.4 \%)$ \\
\hline & & & (95\% Cl 52.5 to 64.9$)$ & $(95 \% \mathrm{Cl} 0.6$ to 4.4$)$ & $(95 \% \mathrm{Cl} 31.4$ to 43.7$)$ \\
\hline Western Canada total & & 1118 & $410(36.7 \%)$ & $37(3.3 \%)$ & $657(58.8 \%)$ \\
\hline & & & (95\% Cl 33.9 to 39.5$)$ & (95\% Cl 2.4 to 4.5$)$ & $(95 \% \mathrm{Cl} 55.9$ to 61.6$)$ \\
\hline
\end{tabular}

NHPs, natural health products.

participating study site. Figure 2 details patient involvement during the two study phases.

\section{Phase II: causality assessment and laboratory analysis}

Nine of the 11 cases with detailed interviews underwent causality assessment; 2 were not assessed due to AEs occurring beyond the 1-month screening timeframe (figure 2). Two of nine cases $(22.2 \%)$ were determined to be 'likely' due to a NHP, with one case likely due to an interaction between one or more NHPs and a prescription drug. A brief summary of each adjudicated case, as well as patient demographics collected, is described in table 4. Laboratory analysis was available for all cases that warranted it, which was determined on a case-by-case basis. Analyses were performed in three reported cases (3, 4 and 5) to assess contribution to causality assessment; significant findings, or lack thereof, are described in table 4 .

\section{DISCUSSION}

Principal findings

Implementing active surveillance into community pharmacies markedly improves the detection of AEs reported by patients taking NHPs. The results indicate that adding one

Table 2 Weighted proportions of participants reporting AEs for those using prescription drugs, NHPs or both, by pharmacy and province

\begin{tabular}{|c|c|c|c|c|c|}
\hline & Pharmacy & $\begin{array}{l}\text { Participants } \\
\text { reporting AE }\left(n_{i}\right)\end{array}$ & $\begin{array}{l}\text { Prescription drug } \\
\text { use AEs }\left(n_{p}\right)\left(p_{p}\right)\end{array}$ & $\begin{array}{l}\text { NHP use only } \\
\text { AEs }\left(n_{n}\right)\left(p_{n}\right)\end{array}$ & $\begin{array}{l}\text { Concurrent use } \\
\text { AEs }\left(n_{c}\right)\left(p_{c}\right)\end{array}$ \\
\hline & AB01 & 5 & $0(0.0 \%)$ & $0(0.0 \%)$ & $5(6.9 \%)$ \\
\hline & AB02 & 8 & $1(3.0 \%)$ & $1(11.1 \%)$ & $6(8.0 \%)$ \\
\hline & AB03 & 10 & $2(6.3 \%)$ & $0(0.0 \%)$ & $8(12.5 \%)$ \\
\hline & AB04 & 19 & $1(1.4 \%)$ & $0(0.0 \%)$ & $8(8.1 \%)$ \\
\hline & AB05 & 3 & $0(0.0 \%)$ & $0(0.0 \%)$ & $3(60.0 \%)$ \\
\hline & AB06 & 5 & $0(0.0 \%)$ & $0(0.0 \%)$ & $5(4.7 \%)$ \\
\hline & AB07 & 3 & $1(6.3 \%)$ & $0(0.0 \%)$ & $2(8.7 \%)$ \\
\hline \multirow[t]{4}{*}{ Alberta total } & & 53 & $\begin{array}{l}5(1.9 \%) \\
(95 \% \mathrm{Cl} 0.8 \text { to } 4.4)\end{array}$ & $\begin{array}{l}1(3.0 \%) \\
(95 \% \mathrm{Cl} 0.4 \text { to } 18.6)\end{array}$ & $\begin{array}{l}47(8.3 \%) \\
(95 \% \mathrm{Cl} 6.3 \text { to } 10.8)\end{array}$ \\
\hline & $\mathrm{BC} 01$ & 0 & $0(0.0 \%)$ & $0(0.0 \%)$ & $0(0.0 \%)$ \\
\hline & $\mathrm{BC} 02$ & 1 & $0(0.0 \%)$ & $0(0.0 \%)$ & $1(4.0 \%)$ \\
\hline & $\mathrm{BCO3}$ & 0 & $0(0.0 \%)$ & $0(0.0 \%)$ & $0(0.0 \%)$ \\
\hline British Columbia total & & 1 & $0(0.0 \%)$ & $0(0.0 \%)$ & $\begin{array}{l}1(1.1 \%) \\
(95 \% \mathrm{Cl} 0.2 \text { to } 7.5)\end{array}$ \\
\hline Western Canada total & & 54 & $\begin{array}{l}5(1.2 \%) \\
(95 \% \mathrm{Cl} 0.51 \text { to } 2.9)\end{array}$ & $\begin{array}{l}1(2.7 \%) \\
(95 \% \mathrm{Cl} 0.4 \text { to } 16.9)\end{array}$ & $\begin{array}{l}48(7.3 \%) \\
(95 \% \mathrm{Cl} 5.6 \text { to } 9.6)\end{array}$ \\
\hline
\end{tabular}

AEs, adverse events; NHPs, natural health products. 
Table 3 ORs of NHP use only and concurrent prescription drug-NHP use compared with prescription drug use only by province

\begin{tabular}{|c|c|c|c|c|}
\hline \multirow[b]{2}{*}{ Province } & \multicolumn{2}{|l|}{ NHP use only } & \multicolumn{2}{|c|}{$\begin{array}{l}\text { Concurrent prescription } \\
\text { drug-NHP use }\end{array}$} \\
\hline & $\overline{\text { OR (95\% Cl) }}$ & p Value & $\overline{\text { OR (95\% Cl) }}$ & $\overline{p \text { Value }}$ \\
\hline Alberta total & 1.66 (0.19 to 14.62$)$ & 0.650 & 4.78 (1.88 to 12.16$)$ & $<0.001$ \\
\hline British Columbia total & NA & - & NA & - \\
\hline Western Canada total & $2.25(0.26$ to 19.78$)$ & 0.465 & 6.38 (2.52 to 16.17$)$ & $<0.001$ \\
\hline
\end{tabular}

or more NHPs to a patient's prescription drug regimen significantly increases the likelihood of reporting an AE. Our study's interview and adjudication process allowed for complete causality assessment of the AEs reported by consenting and interviewed patients, since an $\mathrm{AE}$ is not considered an AR until causality is suspected or confirmed, as well as until meaningful, high-quality AR reports are submitted to Health Canada. The screening questions trialled were brief ${ }^{33}$ and well accepted by pharmacists, allowing full disclosure around NHP use and an opportunity to discuss health outcomes with their patients.

\section{Strengths of the study}

Pharmacy SONAR's active surveillance detected $54 \mathrm{AE}$ reports in 1118 patients screened; in comparison,
Health Canada received 342 spontaneous AR reports involving NHPs during the same time period from a population of approximately 30 million Canadians. ${ }^{34}$ It is arguable whether these data are comparable, as by definition, AR reports assume a causal relationship by whomever submits them, while $\mathrm{AE}$ requires assessment to determine causality. While reports submitted to Health Canada are labelled ARs, they still undergo independent assessment by the regulatory agency to assess causality. Events identified in Pharmacy SONAR were labelled AEs pending adjudication; however, they were obtained through specific questioning about product exposure. We believe that the designation of 'AR' should be reserved until causality assessment has been determined. Our study was able to ascertain AE reports in
Figure 2 Flow diagram of phase I and II results. AE, adverse event; NHP, natural health product.

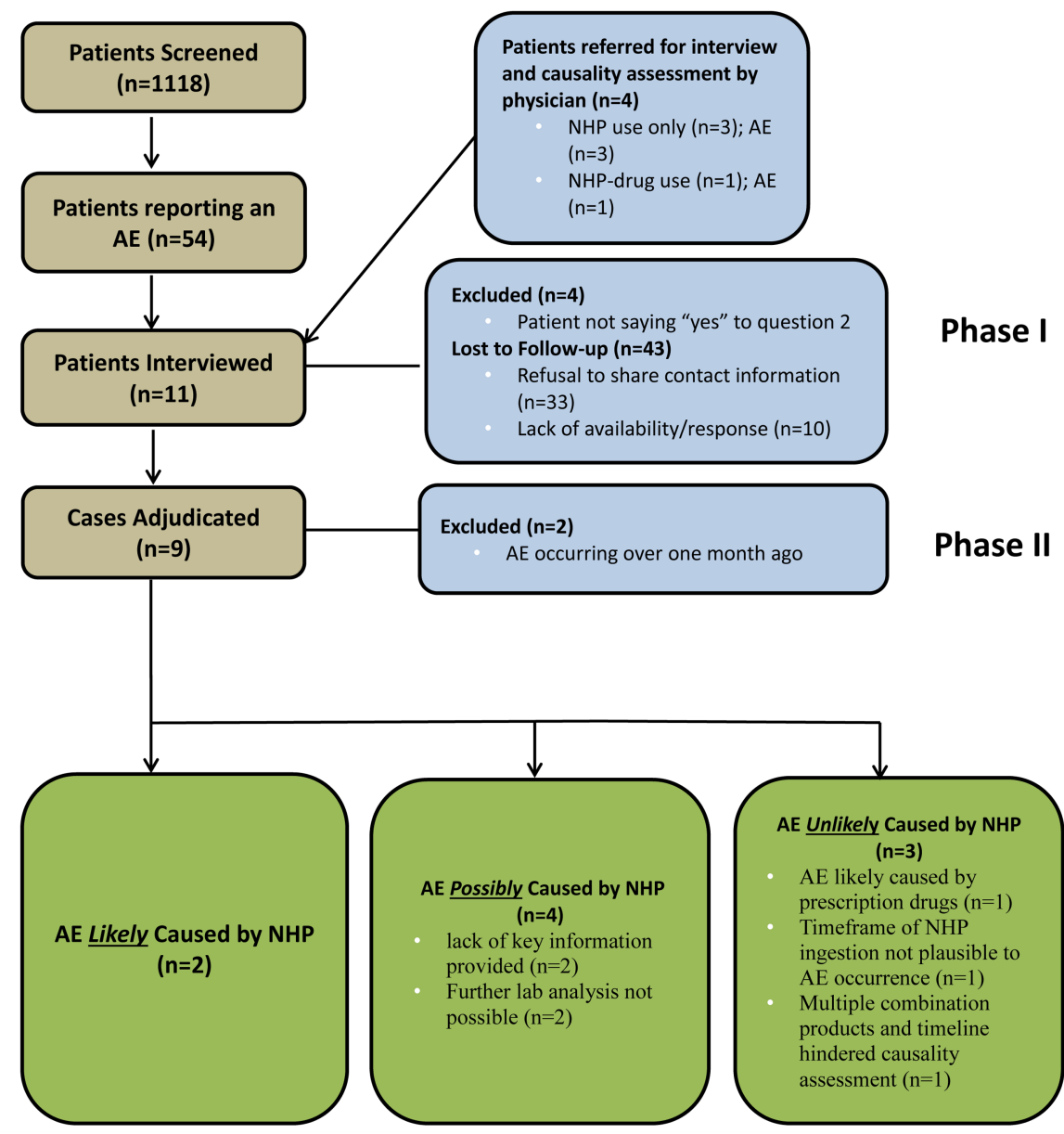


Table 4 Summary of cases for which causality assessment was undertaken

\begin{tabular}{|c|c|c|c|c|c|c|}
\hline Case & $\begin{array}{l}\text { Age } \\
\text { Ethnicity } \\
\text { Sex }\end{array}$ & $\begin{array}{l}\text { Tobacco use; } \\
\text { alcohol use; } \\
\text { ethnicity }\end{array}$ & $\begin{array}{l}\text { Prescription and over-the-counter drugs } \\
\text { (oral administration unless otherwise } \\
\text { specified) }\end{array}$ & $\begin{array}{l}\text { Natural health products } \dagger \text { (brand name, } \\
\text { where known) (oral administration } \\
\text { unless otherwise specified) }\end{array}$ & $\begin{array}{l}\text { Adverse event } \\
\text { description }\end{array}$ & $\begin{array}{l}\text { Outcome of } \\
\text { Causality } \\
\text { assessment }\end{array}$ \\
\hline 1 & $\begin{array}{l}\text { 68-year-old } \\
\text { Caucasian } \\
\text { Female }\end{array}$ & None; none; & $\begin{array}{l}\text { Amlodipine, bisoprolol, ezetimibe, } \\
\text { levothyroxine, ramipril, rosuvastatin, } \\
\text { clopidogrel }\end{array}$ & $\begin{array}{l}\text { Flaxseed oil, omega-3 fatty acids, vitamin } \mathrm{D} \text {, } \\
\text { calcium/magnesium/zinc }{ }^{*}\end{array}$ & Severe bruising & $\begin{array}{l}\text { Likely caused by } \\
\text { NHP }\end{array}$ \\
\hline 2 & $\begin{array}{l}\text { 25-year-old } \\
\text { Caucasian } \\
\text { Female }\end{array}$ & $\begin{array}{l}\text { None; }<1 \text { drink/ } \\
\text { week }\end{array}$ & $\begin{array}{l}\text { Cyproterone acetate/ethinyl estradiol }{ }^{\star} \text {, } \\
\text { ketorolac, escitalopram }\end{array}$ & Calcium carbonate, vitamin $\mathrm{D}$, multivitamin & $\begin{array}{l}\text { Nausea and } \\
\text { vomiting }\end{array}$ & $\begin{array}{l}\text { Likely caused by } \\
\text { NHP }\end{array}$ \\
\hline 3 & $\begin{array}{l}\text { 8.5-year-old } \\
\text { Chinese } \\
\text { Female }\end{array}$ & None; none & $\begin{array}{l}\text { Sertraline, polyethylene glycol, } \\
\text { metoclopramide, mineral oil, fluticasone } \\
\text { propionate inhalation aerosol }\end{array}$ & $\begin{array}{l}\text { Chinese herbal tea; laboratory analysis detected } \\
\text { camphor }\end{array}$ & Cardiac arrest & $\begin{array}{l}\text { Possibly caused } \\
\text { by NHP }\end{array}$ \\
\hline 4 & $\begin{array}{l}\text { 2-year-old } \\
\text { Spanish } \\
\text { Female }\end{array}$ & None; none & None & $\begin{array}{l}\text { Ganoderma lucidum/cocoa (Cocozhi)*; } \\
\text { laboratory analysis detected caffeine }\end{array}$ & Status epilepticus & $\begin{array}{l}\text { Possibly caused } \\
\text { by NHP }\end{array}$ \\
\hline 5 & $\begin{array}{l}\text { 6-month-old } \\
\text { Caucasian/ } \\
\text { Aboriginal } \\
\text { Female }\end{array}$ & None; none & Ibuprofen & $\begin{array}{l}\text { Belladonna/Chamomilla vulgaris/Ferrum } \\
\text { phosphoricum (Camilia-Canadian formulation) }{ }^{\star} \text {, } \\
\text { Chamomilla/Phytolacca decandra/Rheum } \\
\text { officinale (Camilia-USA formulation) }{ }^{\star} \text {, Calcium } \\
\text { carbonicum Hahnemanni/Pulsatilla/Chamomilla/ } \\
\text { Plantago major/Dulcamara/Belladonna } \\
\text { (Viburcol) }^{\star} \text {; no significant findings detected by } \\
\text { laboratory analysis }\end{array}$ & $\begin{array}{l}\text { Absence seizures } \\
\text { and status } \\
\text { epilepticus }\end{array}$ & $\begin{array}{l}\text { Possibly caused } \\
\text { by NHP }\end{array}$ \\
\hline 6 & $\begin{array}{l}\text { 16-year-old } \\
\text { Caucasian/ } \\
\text { Metis } \\
\text { Female }\end{array}$ & $\begin{array}{l}\text { None; 6-7 } \\
\text { drinks/week }\end{array}$ & None & $\begin{array}{l}\text { Rosemary, honey, witch hazel, fenugreek seed, } \\
\text { black seed, King Solomon seed, ginseng } \\
\text { powder, damiana leaves, marshmallow, sage, } \\
\text { juniper berries, chamomile flowers, cloves, } \\
\text { cinnamon, spearmint, thyme (RespirActin) }{ }^{\star}\end{array}$ & $\begin{array}{l}\text { Shallow } \\
\text { breathing, fatigue } \\
\text { and convulsions }\end{array}$ & $\begin{array}{l}\text { Possibly caused } \\
\text { by NHP }\end{array}$ \\
\hline 7 & $\begin{array}{l}60 \text {-year-old } \\
\text { Caucasian } \\
\text { male }\end{array}$ & None; none & $\begin{array}{l}\text { Gabapentin, telmisartan/hydrochlorothiazide*, } \\
\text { simvastatin, amlodipine, naproxen, } \\
\text { oxycodone/acetaminophen, acetaminophen/ } \\
\text { codeine/caffeine* }\end{array}$ & Vitamin C & Vertigo & $\begin{array}{l}\text { Unlikely caused } \\
\text { by NHP }\end{array}$ \\
\hline 8 & $\begin{array}{l}\text { 65-year-old } \\
\text { German/ } \\
\text { French } \\
\text { Female }\end{array}$ & $\begin{array}{l}\text { None; }<1 \text { drink/ } \\
\text { week }\end{array}$ & $\begin{array}{l}\text { Amlodipine, lisinopril, hydrochlorothiazide, } \\
\text { cyclobenzaprine, betahistine }\end{array}$ & $\begin{array}{l}\text { Vitamin D, calcium, magnesium, 14-mushroom } \\
\text { complex }\end{array}$ & $\begin{array}{l}\text { Vertigo, head } \\
\text { 'pain and fullness' }\end{array}$ & $\begin{array}{l}\text { Unlikely caused } \\
\text { by NHP }\end{array}$ \\
\hline $9 \ddagger$ & $\begin{array}{l}\text { 58-year-old } \\
\text { British } \\
\text { Female }\end{array}$ & None; none & Amlodipine & $\begin{array}{l}\text { Several combination products consisting of }>55 \\
\text { individual NHP ingredients }\end{array}$ & $\begin{array}{l}\text { Severe epigastric } \\
\text { pain }\end{array}$ & $\begin{array}{l}\text { Unlikely caused } \\
\text { by NHP }\end{array}$ \\
\hline
\end{tabular}

*Denotes combination products as indicated by a '" between ingredients.

†Products and ingredients are as stated on the manufacturers' product package.

fDetails of case, including all NHPs and their ingredients, have been published elsewhere. ${ }^{49}$

$\mathrm{NHP}$, natural health product. 
specific patient subgroups: those taking prescription drugs only, NHPs only and both concurrently. Another strength of our study is the causality assessment that was available for each $\mathrm{AE}$ reported; however, in practical terms, it was restricted to only those who consented to, and were available for, an interview. Although scheduling patient interviews was not without challenges, all that were completed provided meaningful information to allow for a full adjudication of the AE. Health Canada could not provide information on how many of their 342 reports involving NHPs were assessed for causality. ${ }^{34}$ Many important steps need to be taken before a reported $\mathrm{AE}$ associated with a product can be deemed causal; unfortunately, data collected through passive surveillance systems are often of insufficient quality to support this process. ${ }^{11} 232435$ The knowledge gained through laboratory analysis around constituents and toxicology of NHPs associated with AEs collected in our study allowed insight into the causality of the event.

\section{Limitations of the study}

Only a fraction of patients visiting participating pharmacies was screened in our study; exact information on the proportion screened is not known since pharmacies consider the denominator (number of patients seen) proprietary. Community pharmacists reported time constraints due to high prescription volumes and numerous corporate demands. We attempted weekly phone calls to improve staff involvement, but limited our support to that which could be accomplished remotely (ie, off-site). Seeking pharmacy participation from the store level rather than the corporate level seemed to improve staff engagement. Ideally, the screening questions tested in this study should be built into pharmacists' routine practice in order to gain insight into their patients' health outcomes and monitor health product (drugs and NHPs) safety. Given the Canadian population of 30 million people, the relatively few patients screened in our study do not allow for a definitive conclusion to be drawn; our results are, however, strongly indicative of the potential risks present when combining prescription drug and NHP use.

Biases were also possible given the observational study design. Sampling bias may have occurred with respect to whom, or when, pharmacists screened, based on their workload. Recall bias was minimised limiting the screening history timeframe to 1 month, encouraging patients to obtain information from product bottles during the interview and by confirming information from hospitalisation records.

The data collected from the pharmacies in $\mathrm{BC}$ are not consistent with that of $\mathrm{AB}$, or even $\mathrm{ON} .^{19}$ Even with fewer overall patients screened, the $\mathrm{AE}$ rates found in individual pharmacies are much lower than other pharmacies in $\mathrm{AB}$ and $\mathrm{ON}$ with similar numbers of patients screened. Based on discussion with the pharmacy staff, no clear reasons were provided as to why this may have occurred. It is possible that the number of patients screened at those pharmacies was too few to capture a true $\mathrm{AE}$ rate, or there may be important differences in the number of AEs experienced by patients in this population. At the time of screening, pharmacists in BC were reimbursed by the government to conduct medication history interviews with their patients; this may have prevented or resolved AEs occurring in patients visiting these pharmacies. Further screening is needed to determine whether this variation found is a true difference or not.

Our study sampled patients visiting community pharmacies, who, therefore, are more likely to be taking prescription drugs, allowing us to sample our target population of individuals taking NHPs and drugs concurrently. Macedo et $a l^{36}$ concluded that these patients might be more likely to experience an $\mathrm{AE}$, since the simultaneous exposure to three or more drugs significantly increases the risk of a serious AE. In addition, our study setting could not capture those patients who are hospitalised, due to a serious medical condition or $\mathrm{AE}$, or those who may have experienced an $\mathrm{AE}$ that lead to death. Given that in any given week, over half of Canadians aged 18 years and older visit a pharmacy; community pharmacy was considered to be a suitable study setting to capture the general population. ${ }^{37}$

The NHPs listed in table 4 are stated as on the manufacturers' product packages since this is the information immediately available to someone selling, recommending or purchasing a NHP; typically, manufacturers' packaging did not include full product specifications, and often even basic details, such as plant species and plant part, were absent.

\section{Study findings in the context of previous research}

Results from our study were similar to those collected in our ON pilot study ${ }^{19}$; when these data are combined with those of $\mathrm{AB}$ and $\mathrm{BC}$, estimated national proportions suggest that $45.4 \%(95 \%$ CI $43.8 \%$ to $47.0 \%)$ of Canadians who visit community pharmacies take NHPs and prescription drugs concurrently, and of those, $7.4 \%$ (95\% CI $6.3 \%$ to $8.8 \%$ ) report an AE. To our knowledge, no other national data about AEs associated with concurrent NHP-drug use have been reported previously. Active surveillance in paediatric populations has been studied, finding that $48 \%$ of patients to be using complementary and alternative medicine (CAM) and prescription drugs concurrently and $11 \%$ had potential vitamin and medication interactions. ${ }^{38}{ }^{39}$ In patients of 50-64 years old, $14.2 \%$ were at risk of a potential NHPdrug interaction; this proportion increased to $23.7 \%$ and $38.4 \%$ in those taking 5 or more and 10 or more health products concurrently, respectively. ${ }^{21}$

When looking at NHP safety, other active surveillance systems such as national and provincial drug and disease registries or databases are limited, as most of them lack the ability to record NHP and OTC product use. ${ }^{23}{ }^{40} \mathrm{In}$ addition, many of these registries and databases focus on chronic medical conditions, such as cancer or 
rheumatoid arthritis, ${ }^{23}$ and the general population is not targeted. Menniti-Ippolito et at $t^{41}$ found that active surveillance increased $\mathrm{AE}$ reporting from 4 to 15.1 in 100000 children screened. Similarly, AE reporting in a CAM-specialised primary care setting improved by $148 \%$ when active surveillance was implemented. ${ }^{42}$

Our study results provide similar data to a recent national Health Canada survey, where $73 \%$ of Canadians report taking at least one NHP and $15 \%$ experienced an unwanted reaction. ${ }^{1}$ However, we were able to capture more specific data (ie, how many of those patients were taking a NHP with a prescription drug vs alone) and we identified a markedly higher number of AE reports than Health Canada. ${ }^{1}$ It can be argued that the type of events reported through spontaneous reporting is already suspected to be causally linked to a health product by the reporter, and would therefore be viewed as an AR instead of an AE. It is possible that Pharmacy SONAR captured a higher number of harms due to screening for all AEs, with or without suspicion of causation. However, it is also possible that the first two questions in the screening process may have prompted a patient to link an event to a health product (asking about product use before asking about an $\mathrm{AE}$ ). In addition, the pharmacy staff may have selectively recorded certain AEs over others based on their own knowledge or bias around whether a causal link was plausible.

A survey conducted by Salvo et $a t^{43}$ in southern Italy found that women aged between 18 and 52 years who reported an adverse drug event (ADE) were significantly more likely to be using alternative or complementary medicine than those who reported no ADE $(20.4 \%$ and $8.2 \%$, respectively). This survey also collected data on drug use; however, details around how drugs and complementary medicines were taken (alone or in combination) were not described. ${ }^{43}$ Our study was able to collect such data and, as such, determine whether patients taking both types of products in combination are more likely to experience an $\mathrm{AE}$ than those taking drugs alone.

It is likely that there exists a continuum between food, or dietary compounds, NHPs and drugs, and clinically relevant interactions exist along this spectrum. Studies in the literature report such interactions ${ }^{44-48}$ and further research will likely continue in this area. The data collected in our study involved drug use and NHP use; however, further information was collected on dietary intake during the telephone interview, especially when food or beverages were taken at the same time as NHPs and/or drugs, and considered by the adjudication committee when assessing for causality.

\section{Implications for policy, research and clinical practice}

While passive surveillance systems play an important role in pharmacovigilance, the use of current active surveillance models should be used to complement these systems. ${ }^{22} 23$
Health professionals are encouraged to screen for NHP use and AEs associated with NHP and prescription drug during routine patient care. By improving the rates of $\mathrm{AE}$ identification and reporting, possible harms can be detected sooner, and even prevented. Our study screening questions are brief, taking approximately 15 seconds per patient to administer. ${ }^{19}$ Health professional prompting will increase the discussion around NHPs with their patients as well as improve awareness of the therapies their patients are engaged in so as to improve safety and health outcomes. It is also important for clinicians to consider that there is a continuum from food-functional foods-nutraceuticals-NHPs-OTCs-prescription drugs, and they should be vigilant in collecting a complete medical history from patients around all products taken and any dietary modifications made by patients for the purpose of health.

The data collected during this study will be populated in a database to allow for health professional and researcher access to NHPs, prescription drugs and combinations that have been used with and without reported AEs, as well as details around specific AEs found. The data collected around which prescription drugs and NHPs were taken with and without reports of harm would be valuable to analyse, and would be important to patient safety in the future.

\section{CONCLUSIONS}

Pharmacy SONAR demonstrates that active surveillance of prescription drug and NHP-related AEs in community pharmacies is feasible and increases the rate of $\mathrm{AE}$ detection significantly compared with that of passive surveillance. With methods refined in our pilot study, ${ }^{19}$ we have been able to determine national estimates for NHP, drug and concurrent NHP-drug use and associated AEs. Of particular note, one of the strongest aspects of this study is its ability to assess each case reported for causality, to include laboratory analysis of products and produce high-quality suspected AR reports for the federal regulatory body (in this case, Health Canada).

Future research might include assessing the impact of implementation of active surveillance of NHPs in different healthcare locations, such as hospitals or naturopathic clinics. In addition, it would be valuable to screen patients with chronic medical conditions who may be at higher risk for experiencing AEs. In terms of the study process, methods to improve the number of patients screened and those interviewed after reporting an $\mathrm{AE}$ (loss to follow-up) would allow for a more definitive conclusion to be drawn and more data collected in this area.

Author affiliations

${ }^{1}$ Faculty of Pharmacy and Pharmaceutical Sciences, University of Alberta, Edmonton, Alberta, Canada

${ }^{2}$ Faculty of Medicine and Dentistry, University of Alberta, Edmonton, Alberta, Canada

${ }^{3}$ Leslie Dan Faculty of Pharmacy, University of Toronto, Toronto, Ontario, Canada 
${ }^{4}$ Faculty of Medicine, University of Ottawa, Ottawa, Ontario, Canada

${ }^{5}$ Department of Laboratory Medicine and Pathology, University of Alberta Hospital, Edmonton, Alberta, Canada

${ }^{6}$ Laboratory Services, University of Alberta Hospital, Alberta Health Services, Edmonton, Alberta, Canada

${ }^{7}$ Marketed Biologicals, Biotechnology and Natural Health Products Bureau, Marketed Health Products Directorate, Health Canada, Ottawa, Ontario, Canada ${ }^{8}$ Faculty of Medical and Health Sciences, School of Pharmacy, University of Auckland, Auckland, New Zealand

${ }^{9}$ School of Pharmacy, Curtin Health Innovation Research Institute, Perth, Australia

${ }^{10}$ Department of Biology, Faculty of Science, University of Ottawa, Ottawa, Ontario, Canada

${ }^{11}$ Alan Edwards Pain Management Unit, McGill University Health Centre, Montreal, Quebec, Canada

${ }^{12}$ Department of Pediatrics, Faculty of Medicine and Dentistry, University of Alberta, Edmonton, Alberta, Canada

Acknowledgements The authors would like to thank Hitesh Bhatt for his assistance in data analysis.

Contributors $\mathrm{CN}$ initiated the project, responsible for design and methodology, interviewed the patient presented in case report and wrote manuscript (including final draft). RTT participated in original conception and design of the project, case adjudication, supervised project and reviewed all drafts of manuscript. HB supervised project, participated in original conception and design of the project and reviewed all drafts of manuscript. $\mathrm{JB}$, MAW and TLC participated in original conception and design of the project, case adjudication and reviewed final draft of manuscript. JTA, DL, GC and BCF participated in original conception and design of the project, case adjudication, laboratory analysis and reviewed final draft of manuscript. MM participated in original conception and design of the project, provided support from Health Canada and reviewed final draft of manuscript. RJR participated in original conception and design of the project, provided graduate student statistical support and reviewed final draft of manuscript. SV is the primary supervisor of project, participated in original conception and design of the project, and reviewed all drafts of manuscript.

Funding This work was funded by the Canadian Institute of Health Research, Health Canada, Canadian Patient Safety Institute.

Competing interests SV receives salary support from the Canadian Institute of Health Research and holds an Alberta Heritage Foundation for Medical Research Health Scholar Award. RJR receives salary support by Alberta Innovates - Health Solutions (Edmonton, Canada) as a Health Scholar.

Ethics approval Human Research and Ethics Board, University of Alberta.

Provenance and peer review Not commissioned; externally peer reviewed.

Data sharing statement Researchers can access the data collected in this study through the corresponding author.

Open Access This is an Open Access article distributed in accordance with the Creative Commons Attribution Non Commercial (CC BY-NC 3.0) license, which permits others to distribute, remix, adapt, build upon this work noncommercially, and license their derivative works on different terms, provided the original work is properly cited and the use is non-commercial. See: http:// creativecommons.org/licenses/by-nc/3.0/

\section{REFERENCES}

1. Natural Health Products Directorate-Health Canada. Natural Health Product Tracking Survey-2010 Final Report. Ipsos-Reid. March 13 2011. http://epe.lac-bac.gc.ca/100/200/301/pwgsc-tpsgc/por-ef/ health/2011/135-09/report.pdf (accessed 30 Mar 2012).

2. Vicki Wood. OTC Market Report 2012: introduction. Canadian Healthcare Network. 2012. http://www.canadianhealthcarenetwork. $\mathrm{ca} /$ pharmacists/clinical/otc/otc-market-report-2012-introduction-16126 (accessed 11 Nov 2012)

3. Walji R, Boon $\mathrm{H}$, Barnes $\mathrm{J}$, et al. Reporting natural health product related adverse drug reactions: is it the pharmacist's responsibility? Int J Pharm Pract 2011;19:383-91.
4. Barnes PM, Stussman BJ, Bloom B. Costs of complementary and alternative medicine (CAM) and frequency of visits to CAM practitioners: United States, 2007. Natl Health Stat Report 2009;1-14.

5. Xue CC, Zhang AL, Lin V, et al. Complementary and alternative medicine use in Australia: a national population-based survey. $J$ Altern Complement Med 2007;13:643-50.

6. Corazza M, Borghi A, Lauriola MM, et al. Use of topical herbal remedies and cosmetics: a questionnaire-based investigation in dermatology out-patients. J Eur Acad Dermatol Venereol 2009;23:1298-303.

7. Natural Health Products Regulations. Food and Drugs Act. Health Canada. 2003. http://gazette.gc.ca/archives/p2/2003/2003-06-18/ $\mathrm{html} /$ sor-dors196-eng.html (accessed 11 Nov 2012).

8. Felix S. OTC Market Report 2009: more often, self-care means going natural. Canadian Healthcare Network. 1 April 2009. http:// www.canadianhealthcarenetwork.ca/pharmacists/clinical/otc/otcmarket-report-2009-more-often-self-care-means-going-natural-1055 (accessed 11 Nov 2012).

9. Charrois TL, Hill RL, Vu D, et al. Community identification of natural health product drug interactions. Ann Pharmacother 2007:41:1124-9.

10. Wysong P. $38 \%$ of doctors now suggest natural health products: survey. Canadian Healthcare Network. May 18, 2011. http://www. canadianhealthcarenetwork.ca/pharmacists/clinical/health-indextherapeutics/alternative-medicine/38-of-doctors-now-suggest-naturalhealth-products-survey-11135 (accessed 11 Nov 2012).

11. Shaw $D$, Ladds $G$, Duez $P$, et al. Pharmacovigilance of herbal medicine. J Ethnopharmacol 2012;140:513-18.

12. Barnes J. Pharmacovigilance of herbal medicines: a UK perspective. Drug Saf 2003;26:829-51.

13. Walji R, Boon H, Barnes J, et al. Adverse event reporting for herbal medicines: a result of market forces. Healthc Policy 2009;4:77-90.

14. Posadzki P, Watson L, Ernst E. Contamination and adulteration of herbal medicinal products (HMPs): an overview of systematic reviews. Eur J Clin Pharmacol 2013;69:295-307.

15. Chitturi S, Farrell G. Hepatotoxic slimming aids and other herbal hepatotoxins. J Gastroenterol Hepatol 2008;23:366-73.

16. Roy-Byrne PP, Bystritsky A, Russo J, et al. Use of herbal medicine in primary care patients with mood and anxiety disorders. Psychosomatics 2005;46:117-22.

17. Quandt SA, Chen H, Grzywacz JG, et al. Use of complementary and alternative medicine by persons with arthritis: results of the National Health Interview Survey. Arthritis Rheum 2005:53:748-55.

18. Wood MJ, Stewart RL, Merry $\mathrm{H}$, et al. Use of complementary and alternative medical therapies in patients with cardiovascular disease. Am Heart J 2003;145:806-12.

19. Vohra S, Cvijovic K, Boon H, et al. Study of natural health product adverse reactions (SONAR): active surveillance of adverse events following concurrent natural health product and prescription drug use in community pharmacies. PLOS ONE 2012;7:e45196.

20. Morgan TK, Williamson M, Pirotta M, et al. A national census of medicines use: a 24-hour snapshot of Australians aged 50 years and older. Med J Aust 2012;196:50-3.

21. Tessa KM, Margaret $\mathrm{W}$, Jared $\mathrm{AB}$, et al. Medication safety issues in older Australians. Results from a national medicines census. Joint ASCEPT-APSA conference 2012, Sydney Convention and Exhibition Centre, Sydney, Australia, December 2-5, 2012. Australian Society of Clinical and Experimental Pharmacology and Therapeutics-Australian Pharmaceutical Science Association.

22. Pal S, Dodoo A, Mantel A, et al. The World Medicines Situation 2011: pharmacovigilance and safety of medicines. World Health Organization 2011. http://apps.who.int/medicinedocs/documents/ s18771en/s18771en.pdf (accessed 11 Nov 2012)

23. Wiktorowicz ME, Lexchin J, Moscou K, et al. Keeping an eye on prescription drugs, keeping Canadians safe: a commissioned discussion paper. Health Council of Canada $2010 \mathrm{http}: / /$ publications. gc.ca/collections/collection_2011/ccs-hcc/H174-21-2010-eng.pdf (accessed 30 Mar 2012).

24. World Health Organization (WHO). Note for guidance on clinical safety data management: definitions and standards for expedited reporting. Geneva: Author; 1995. CPMP/ICH.377/95.

25. van Grootheest $\mathrm{K}$, Olsson S, Couper M, et al. Pharmacists' role in reporting adverse drug reactions in an international perspective. Pharmacoepidemiol Drug Saf 2004;13:457-64.

26. Raynor DK, Dickinson R, Knapp P, et al. Buyer beware? Does the information provided with herbal products available over the counter enable safe use? BMC Med 2011;9:94

27. Ulbricht CE, Basch EM. eds. Natural standard herb \& supplement reference: evidence-based clinical reviews. St Louis, MO: Elsevier Mosby, 2005. 
28. Cvijovic $\mathrm{K}$, Boon $\mathrm{H}$, Brulotte $\mathrm{J}$, et al. A tool for rapid identification of potential herbal medicine-drug interactions. Can Pharm $J$ 2009;142:224-7.

29. WHO adverse drug event causality assessment criteria, Uppsala drug monitoring centre. http://www.who-umc.org/DynPage.aspx? id=22682. (accessed 2012 Apr 6).

30. Naranjo CA, Busto U, Sellers EM, et al. A method for estimating the probability of adverse drug reactions. Clin Pharmacol Ther 1981;30:239-45.

31. Horn JR, Hansten PD, Chan LN. Proposal for a new tool to evaluate drug interaction cases. Ann Pharmacother 2007;41:674-80.

32. Stata data analysis and statistical software version 12.0. StataCorp LP. Texas, USA.

33. Cvijovic K, Boon $\mathrm{H}$, Jaeger W, et al. Pharmacists' participation in research: a case of trying to find the time. Int $J$ Pharm Pract 2010;18:377-83.

34. Marketed Health Products Directorate. Memo. 30 May 2012

35. Hazell L, Shakir SA. Under-reporting of adverse drug reactions: a systematic review. Drug Saf 2006;29:385-96.

36. Macedo AF, Alves $\mathrm{C}$, Craveiro $\mathrm{N}$, et al. Multiple drug exposure as a risk factor for the seriousness of adverse drug reactions. J Nurs Manag 2011;19:395-9.

37. Canadian Pharmacists Association. Expanding the role of pharmacists. http://pharmacists-ca.inf.ca/content/consumer_patient/ resource_centre/working/pdf/Expanding_the_Role_of_Pharmacists_ Mar07.pdf (accessed 30 Oct 2012).

38. Jean D, Cyr C. Use of complementary and alternative medicine in a general pediatric clinic. Pediatrics 2007;120:e138-41.

39. Goldman RD, Vohra S, Rogovik AL. Potential vitamin-drug interactions in children at a paediatric emergency department. Paediatr Drugs 2009;11:251-7.
40. Pharmanet. Ministry of Health. Government of British Columbia http://www.health.gov.bc.ca/pharmacare/pharmanet/netindex.html (accessed 30 Oct 2012).

41. Menniti-Ippolito G, Raschetti R, Da Cas R, et al. Active monitoring of adverse drug reactions in children. Lancet 2000;355:1613-14.

42. Talabi M, Jeschke $E$, Bockelbrink $A$, et al. Educational intervention to improve physician reporting of adverse drug reactions (ADRs) in a primary care setting in complementary and alternative medicine. BMC Public Health 2009:9:274.

43. Salvo F, Miroddi M, Alibrandi A, et al. Attitudes and opinion about adverse drug events of women living in a city of south Italy. Pharmacology 2013:91:173-7.

44. MacDonald L, Foster BC, Akhtar H. Food and therapeutic product interactions - a therapeutic perspective. J Pharm Pharm Sci 2009;12:367-77.

45. Agbonon A, Eklu-Gdegbeku K, Kodjo, et al. In vitro inhibitory effect of West African medicinal and food plants on human cytochrome P450 3A subfamily. J Ethnopharmacol 2010;128:390-4.

46. Cvijovic K, Boon $\mathrm{H}$, Jaeger W, et al. SONAR group. Polypharmacy, multiple natural health products and hepatotoxicity. CMAJ 2011;183: E1085-9.

47. Sheehan NL, van Heeswijk RP, Foster BC, et al. The effect of $\beta$-carotene supplementation on the pharmacokinetics of nelfinavir and its active metabolite M8 in HIV-1-infected patients. Molecules 2012;17:688-702.

48. Foster BC, Arnason JT, Saleem A, et al. Comparative study of hops-containing products on human cytochrome P450-mediated metabolism. J Agric Food Chem 2011;59:5159-63.

49. Necyk C, Barnes J, Tsuyuki RT, et al. How well do pharmacists know their patients? A case report highlighting natural health product disclosure. Can Pharm J 2013;146:202-9. 